\title{
Prevalence of Haemoparasites in village chickens (Gallus gallus domesticus) slaughtered at poultry markets in Maiduguri, Northeastern Nigeria
}

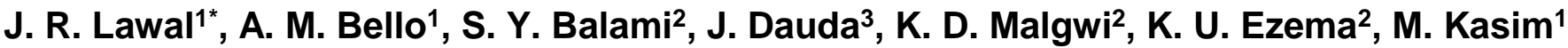 \\ and $\mathrm{A} . \mathrm{A} \cdot \mathrm{Biu}^{4}$ \\ ${ }^{1}$ Department of Veterinary Medicine, Faculty of Veterinary Medicine, University of Maiduguri, P.M.B 1069, Maiduguri, \\ Borno State, Nigeria. \\ ${ }^{2}$ Department of Veterinary Public Health and Preventive Medicine, Faculty of Veterinary Medicine, University of \\ Maiduguri, P.M.B 1069, Maiduguri, Borno State, Nigeria. \\ ${ }^{3}$ Veterinary Teaching Hospital, Faculty of Veterinary Medicine, University of Maiduguri, P.M.B 1069, Maiduguri, Borno \\ State, Nigeria. \\ ${ }^{4}$ Department of Veterinary Microbiology and Parasitology, Faculty of Veterinary Medicine, University of Maiduguri, P.M.B \\ 1069, Maiduguri, Borno State, Nigeria. \\ *Corresponding author. Email: rabanajallailudeen@yahoo.com
}

Copyright (C 2016 Lawal et al. This article remains permanently open access under the terms of the Creative Commons Attribution License 4.0, which permits unrestricted use, distribution, and reproduction in any medium, provided the original work is properly cited.

Received 25th July, 2016; Accepted 21st August, 2016

\begin{abstract}
The present study on prevalence of haemoparasites in village chickens (Gallus gallus domesticus) in Maiduguri comprising the Maiduguri Metropolitan Council (MMC) and Jere district of Borno State, Nigeria was done between November, 2015 and January, 2016. A total of 200 blood samples were collected from chickens of both sexes slaughtered in poultry market/dressing slabs located in Custom market and Monday market Maiduguri and transported to the teaching and research laboratory department of Veterinary Medicine, University of Maiduguri Nigeria, for analysis. Giemsa-stained thin blood smears were prepared and screened for the presence of haemoparasites. Microscopic examination of the thin blood smears revealed that thirty-four (34) of the sampled chickens were infected with at least one genus of haemoparasites, with overall prevalence of $17.0 \%$ for Haemoproteus, and/or Plasmodium spp. Result also revealed that single infection with Haemoproteus spp. shows higher prevalence (50.9\%) than Plasmoduim spp. (29.4\%) or mixed infection with Plasmodium spp. + Haemoproteus spp. (17.6\%). There was higher sex specific prevalent rate in cock $(20.5 \%)$ than in Hen (11.5\%). There was also a strong association between sex and presence of haemoparasite in village chicken $\left(x^{2}=3.09\right)$. However, the distribution of the haemoparasites among the sex of the host chickens was not statistically significant $(P>0.05)$. Similarly the likelihood of getting more haemoparasite in male (cock) than in female (hen) is less $(\mathrm{OR}=0.73$, and $95 \% \mathrm{Cl}=0.344-1.561)$.
\end{abstract}

Keywords: Avian haemoparasites, Maiduguri, Northeastern Nigeria, prevalence, village chickens.

\section{INTRODUCTION}

Poultry production specifically includes chickens, ducks, guinea fowl, turkey and ostrich (Opara et al., 2012). Turkey and chicken productions however make up the main component of the commercial poultry (Opara et al., 2012). Chicken is one of the most intensively reared of the domesticated poultry species and the most developed and profitable animal production enterprise. Poultry production in Africa and parts of Asia is still distinctively divided into commercialized and village enterprise subsector, each with its peculiarities (Muchadeyi et al., 2005). The domestic chickens (Gallus domesticus) likely had its ancestry in the red jungle fowl Gallus gallus that originated from Asia. It appears that people probably domesticated chickens over 4,000 years ago, after 
centuries of hunting wild jungle fowl for food (Page and Daniel, 2000) Village chickens are always associated with free-range management systems in rural areas or as backyard flocks in urban and peri-urban areas of most developing countries including Nigeria (Bebora et al., 2005). The types of feed used for this group of chickens and their feeding systems are also very typical to their group and different from those used for commercial breeds in intensive commercial farms (Bebora et al., 2005). The village chickens are however very important component in the life of villagers or those living in the rural areas (Bebora et al., 2005). Village chickens contribute immensely to rural employment of youths, serves as sources of protein to family nutrition and also serve as source of petty income (sale of eggs and birds) (Kiptarus, 2005). They also form part of cultural life of the rural dwellers used for sacrifices during cultural festivals and ceremonies as well as gifts to visitors and relatives (Bebora et al., 2005). Unfortunately, the Gallus domesticus can easily be infested with several types of bacterial, viral, fungal and parasitic pathogen. (Soulsby, 1982). Parasitism ranks high among factors that threaten chicken production (Mapiye et al., 2008). Among the various parasitic diseases, haemoparasites infections are the most prevalent (Soulsby, 1982). These include a number of parasites which are widely distributed in developing countries and contributing significantly to the low productivity of village chickens (Poulsen et al., 2000). Haemosporidian parasites are common blood parasites of reptiles, birds, and mammals with some stages of development in both tissues and circulating blood cells of infected hosts (Archawaranon, 2005). The most commonly recorded parasites in smears of peripheral blood are unicellular eukaryotic parasites of the genera, Haemoproteus, Leucocytozoon and Plasmoduim (Benedikt et al., 2009). These pathogens are widespread and commonly include species from the genera Plasmodium, Haemoproteus, Leucocytozoon, Fallisia and Trypanosoma (Valkiūnas, 2005; Braga et al., 2011).

Avian haemoparasites are known to be pathogenic to their hosts causing high mortalities (Merino et al., 2000; Cardona et al., 2002), these blood parasites can exert important selection pressure on their hosts through effects on survival (Sol et al., 2003; Møller and Nielsen, 2007), on reproductive success (Merino et al., 2000; Sanz et al., 2001; Marzal et al., 2005; Knowles et al., 2011), on plumage colouration with important ecological and evolutionary consequences, such as changes in community structure (Sol et al., 2003; Marzal et al., 2005; Dunn et al., 2011).

Haemoproteus species have worldwide distribution, due to migration of birds, low parasite specificity, combination of high host mobility and the limited specificity in host vector choice (Valkiunas et al., 2005). The presence of avian Haematozoa has been reported in different areas of the world such as Italy, Bolivia, Malaysia, Czechoslovakia, India, Tanzania and Pakistan
(Permin et al., 2002; Gimba et al., 2014), Nigeria (Usmana et al., 2012; Karamba et al., 2012), Ghana (Poulsen et al., 2000), Zimbabwe (Permin et al., 2002), Malawi (Njunga, 2003) and South Africa (Schultz and Whittington, 2005). This study aimed to determine the prevalence and type of avian haemoparasites parasitizing village chickens (Gallus gallus domesticus) in Maiduguri, Northeastern Nigeria and to provide data that can be serve as references in future research on village chickens in the study area.

\section{MATERIALS AND METHODS}

\section{Description of the study area}

Maiduguri is the capital of Borno state (Figure 1). It is located in the Sahel Savanna region of north-eastern Nigeria at latitude $11^{\circ} 05^{\prime}$ North and longitude $13^{\circ} 05^{\prime}$ East and at about $350 \mathrm{~m}$ above sea level. Maiduguri has mean annual rainfall and temperature of about $630 \mathrm{~mm}$ and $32^{\circ} \mathrm{C}$ respectively, but temperature can go as high as 45 to $48^{\circ} \mathrm{C}$ in the month of March to May. It is the largest city in northeastern Nigeria. Modern Maiduguri was founded in 1907 near the old town of Maiduguri founded in 1672. The population of Maiduguri is estimated to have crossed one million by 2009 . There are many ethnic groups living in the town including Kanuri, Shuwa Arab, Babur/Bura and others. The city is a rail, road, and air transportation center serving north-eastern Nigeria and parts of Niger (www.bornostate.com).

\section{Collection of blood samples}

Two hundred (200) blood samples were collected at alternative days from adult village chickens of both sexes that were presented for slaughter at poultry dressing slabs in Maiduguri Metropolitan poultry markets. The poultry markets/ poultry dressing slabs includes: Custom market and Monday market. Blood sample were collected immediately into heparinized (ethylene diamine tetra acetic acid) sample bottled from the severed jugular vein following slaughter. Samples bottles were appropriately labeled, stored in a cold pack and immediately transported to the teaching and research laboratory, Department of Veterinary Medicine, Faculty of Veterinary Medicine, University of Maiduguri for diagnostic procedures.

\section{Making of thin blood film}

A smear was prepared from blood sample using a clean grease free glass slide, a drop of blood was put on the slide and spread with another glass slide that was placed and hold at an angle 40 to $45^{\circ}$ and push forward firmly, 


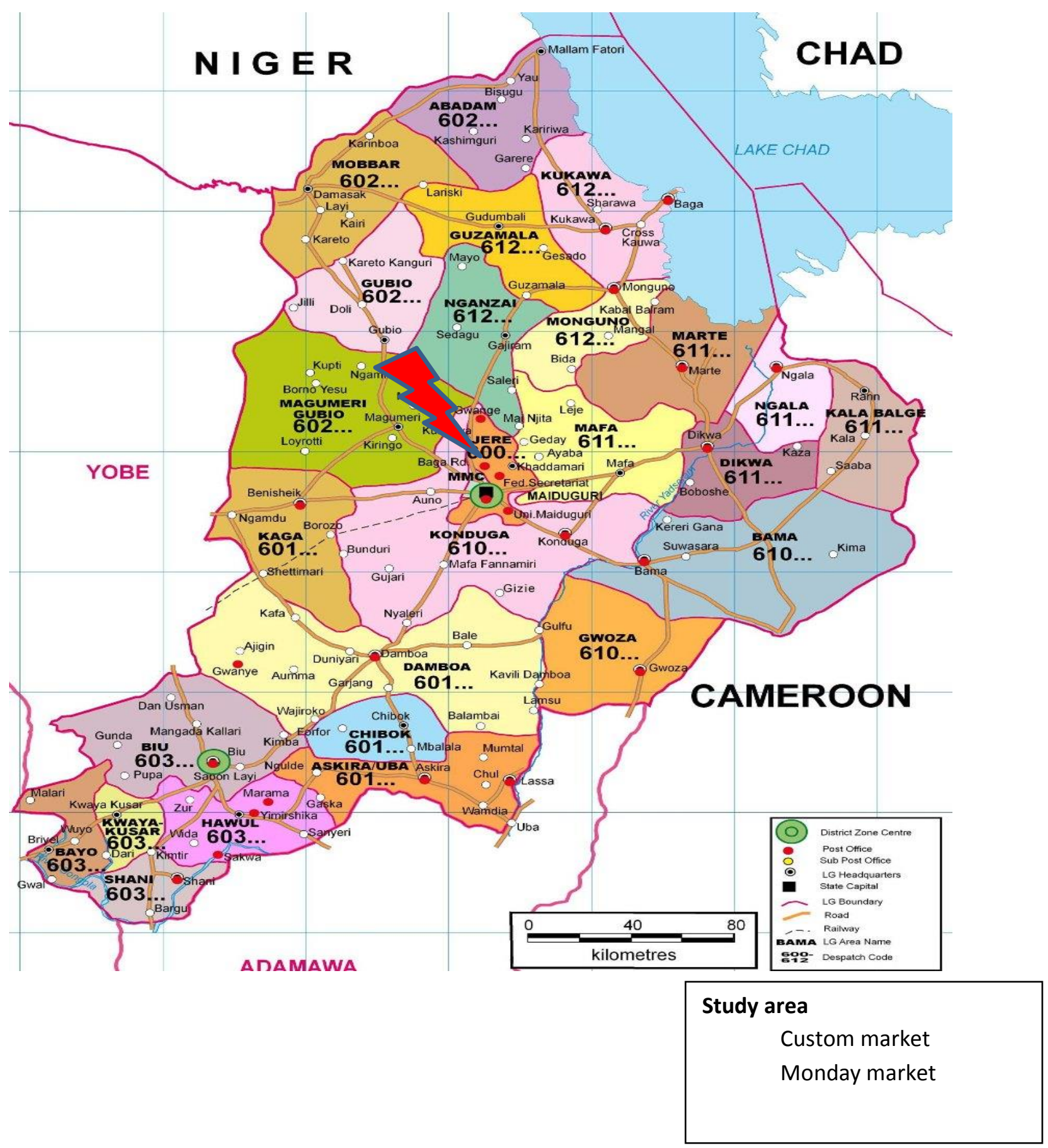

Figure 1. Map of Borno State showing the study area (Maiduguri metropolitan council (MMC) and Jere) with a red pointer.

the blood spread along with the movement of the spreader to have head, body and tail. The blood smear was allowed to air dry for five to ten minutes and was later fixed with absolute methanol (methyl alcohol) according to the standard procedure described by Cheesbrough (2000). The fixed labeled slides were arranged in a dry plastic slide packs.

\section{Staining of slides}

After having a successful well labeled fixed blood smear that has head, body and tail. One in ten (1/10) dilution of Giemsa stain with buffer distilled water $(\mathrm{pH} 7.2)$ was prepared (using $9 \mathrm{ml}$ buffer distilled water in $1 \mathrm{ml}$ of the Giemsa stain). The slides were parked in coupling jar and 
Table 1. Overall prevalence of avian haemoparasites in Village chickens slaughtered at Maiduguri poultry markets/dressing slabs, semi-arid zone of Nigeria.

\begin{tabular}{lcccccc}
\hline $\begin{array}{l}\text { Poultry Markets } \\
\text { /dressing slabs }\end{array}$ & No .examined & No. Positive & Prevalence (\%) & P value & \multicolumn{2}{c}{$\begin{array}{c}\text { 95\% confidence } \\
\text { interval }\end{array}$} \\
\hline Custom market & 100 & 20 & 20.0 & & LL & UL \\
Monday market & 100 & 14 & 14.0 & 0.289 & 0.308 & 1.375 \\
Total & 200 & 34 & $17.0^{*}$ & & & \\
\hline
\end{tabular}

Chi square value was $\left(X^{2}=4.176\right)$ and odd ratio was 0.651 .

Table 2. Prevalence of single and mixed infection of avian haemoparasites in Village chickens slaughtered at the Maiduguri poultry markets/dressing slabs, semi-arid zone of Nigeria.

\begin{tabular}{llcc}
\hline Infection & $\begin{array}{l}\text { Genera of avian Haemoparasites } \\
\text { encountered }\end{array}$ & $\begin{array}{c}\text { Number of positive } \\
\text { samples }\end{array}$ & Percentage (\%) \\
\hline \multirow{2}{*}{ Single Infection } & Haemoproteus spp. & 18 & 52.9 \\
\cline { 2 - 3 } Mixed Infection & Plasmodium spp & 10 & 29.4 \\
Total & Plasmodium spp. & 6 & 17.6 \\
& Haemoproteus spp. & 34 & $100 \%$ \\
\hline
\end{tabular}

allowed to stay 45 minutes. The slides were then removed, washed and placed in upright position to air dry according to the standard procedure described by Cheesbrough (2000).

\section{Microscopic examination of stained slides}

Microscopic examination of stained slide for the presence or absence of haemoparasites were done using oil immersion lens $(\times 100)$. Examination for blood parasites was carried out on tail while head was used for the labeling according to the standard procedure described by Cheesbrough (2000). Parasites are identified based on the morphological changes of the RBC as previously described by Valkiûnas (2005). Positive slides were recorded, further examined by a well and more experienced microscopist from the Teaching and Research laboratory of the Department of Veterinary Medicine, University of Maiduguri.

\section{Data analysis}

Statistical analysis was performed using Chi square test with SPSS (statistical) software version 20 to test association of sex of chicken with the presence or absence of infection (variable that reflect prevalence, define as infection status: $\mathrm{N}=$ not infected chicken, $\mathrm{PP}=$ positive for Plasmodium spp, $\mathrm{PH}=$ positive for Haemoproteus spp and $\mathrm{PHP}=$ mixed infection with Haemoproteus spp + Plasmodium spp.).

\section{RESULTS}

Table 1 shows the overall prevalence of avian
Haemoparasites in Village chickens slaughtered at the major poultry markets/dressing slabs namely: Custom Market and Monday Market in Maiduguri metropolitan council. Out of the two hundred (200) blood samples collected and examined microscopically for the presence or absence of avian haemoparasites, thirty four (34) were positive with an overall prevalence rate of $17.0 \%$. The findings also show that the relative prevalence of avian haemoparasites is higher in samples collected from Custom Market (20.0\%) than Monday Market (14\%).

Table 2 shows the result of the genera of avian haemoparasites encountered in Village chickens slaughtered at poultry markets/dressing slabs in Maiduguri. Two genera of avian haemoparasites which includes Haemoproteus spp. and Plasmodium spp. were encountered in the infected blood samples (34). Each of these parasites occurred in a single infection at a relative prevalent rate of $18(52.9 \%)$ and $10(29.4 \%)$ respectively. Mixed infection with Haemoproteus spp. + Plasmodium spp. were also encountered in some of the blood samples at a relative prevalent rate of $6(17.6 \%)$.

Table 3 shows the result of prevalence of avian haemoparasites in village chickens slaughtered in Maiduguri poultry markets/dressing slabs based on sex of chickens. Out of the 112 blood samples collected from Cocks and 88 from Hens, $23(20.5 \%)$ and 11 (12.5\%) chickens were found positive for different genera of avian haemoparaites respectively.

\section{DISCUSSION}

This study was conducted using the microscopy diagnostic method that is considered in most haemoparasitology as the "gold standard" diagnostic 
Table 3. Prevalence of avian Haemoparasites in village chickens according to sex slaughtered at poultry Market/dressing slabs in Maiduguri, semi-arid zone of Nigeria.

\begin{tabular}{lcccccc}
\hline Sex & $\begin{array}{c}\text { Number of Samples } \\
\text { examined }\end{array}$ & $\begin{array}{c}\text { Number of Positive } \\
\text { samples }\end{array}$ & Prevalence (\%) & P value & \multicolumn{2}{c}{$\begin{array}{c}\text { 95\% confidence } \\
\text { interval }\end{array}$} \\
\hline Cock & 112 & 23 & 20.5 & & LL & UL \\
Hen & 88 & 11 & 12.5 & 0.420 & 0.344 & 1.561 \\
Total & 200 & 34 & $17^{*}$ & & & \\
\hline
\end{tabular}

Chi square value was $\left(X^{2}=3.09\right)$ and odd ratio was 0.73 .

technique for detection of blood parasites (Valkiûnas et al., 2005). The result of this study revealed the prevalence of avian haemoparasites in Village chickens (Gallus gallus domesticus) slaughter at the major poultry markets/dressing slabs in Maiduguri; semi-arid zone of Nigeria. Out the 200 blood samples collected and microscopically observed for the presence of avian haemoparasites, 34 chickens were infected with an overall prevalence of $17 \%$. They were infected with Haemosporidia which includes parasites from two genera namely Haemoproteus spp and Plasmodium spp. This report is consistent with that of Karamba et al. (2012) who have also reported the same genera of avian haemoparasite in domesticated and wild birds in Kano State, Nigeria. Although, the findings of this present study differs from the numbers of previously reported genera of avian haemoparasites in village chickens in Malaysia (Siong et al., 2010; Gimba et al., 2014), Iraq (Shadan, 2013; Hasson, 2015), Kenya (Sabuni et al., 2011), Zimbabwe (Permin et al., 2002) and Nigeria (Sadiq et al., 2003; Usmana et al., 2012). Most of these studies have reported the prevalence of three or more genera of avian haemoparasites in Village chickens which includes Haemoproteus species, Plasmodium species, Leucozytozoon and Trypanosoma species. The present study did not detect Leucocytozoon species, Trypanosoma species, Babesia species nor Filaria species from samples examined. The difference in the findings could be as a result of differences in habitat, climate, behaviour and diet of chickens (Siong et al., 2010). In addition, it is likely that the differences in the prevalence of avian haemoparasites infection reported are due to factors related to the methods used for diagnosis, vector/arthropod breeding season, sampling effort and location, including poultry species and the abundance of arthropod vectors responsible for transmitting the parasites (Braga et al., 2011; Gimba et al., 2014; Bell et al., 2015). The prevalence rate of $17.0 \%$ of avian haemoparasites reported in present study is in line with $19.56 \%$ that was reported by Karamba et al. (2012) but lower than $79.2 \%$ and $76.0 \%$ reported by Sabuni et al. (2011) and Hasson (2015) respectively.

The positive samples found were either infected with single or mixed infection. Single infection with either Plasmodium spp. or Haemoproteus spp. occurred at a prevalent rates of 10 (29.4\%) and 18 (52.9\%) respectively, Haemoproteus spp. was the most prevalent avian haemoparasite in village chickens in this present study. This finding is consistent with previous report by Permin et al. (2002); Gimba et al. (2014) and Hasson (2015) who also reported that Haemoproteus spp. is the most frequently encountered avian haemoparasites in Village chickens in their respective study area. However, the findings of this study contrast that of Sadiq et al. (2003) and Shadan (2013) who reported Plasmodium spp as the most encountered avian haemoparasites in their study areas.

Mixed infection with two haemoprasites (Plasmodium spp.+ Haemoproteus spp.) was found at a prevalent rate of $6(17.6 \%)$. This finding also agreed with previous report by Hasson (2015). This variation can be adequately attributed to variation between agro climatic conditions and availability of arthropod vectors (Permin et al., 2002).

The result of this present study revealed that there was higher specific prevalent rate of haemoparasite in male chickens $(20.5 \%)$ as compared to the female chickens $(11.5 \%)$. There was also a strong statistical association between sex of birds and the presence of haemoparasite in infected village chicken $\left(x^{2}=3.09\right)$. However, the distribution of the haemoparasites among the sex of the host chickens was not statistically significant $(P>0.05)$. Similarly there was no much likelihood of getting more haemoparasite in relation to sex $(\mathrm{OR}=0.17$, and $95 \%$ $\mathrm{Cl}=0.17-0.22$ ). This finding is consistent with previous report by Al-Barwari and Saeed (2012) but contrast the findings of Hasson (2015) who reported high prevalence in female than male chicken. The higher prevalence of avian haemoparasites in male chickens as reported in this present study may be attributed to the abundance of predilection site for blood seeking arthropods. This is connected to the facts that male chickens anatomically have larger comb and wattle which are well supplied with blood vessels that may attract blood sucking arthropods for blood meal during which they may transmit haemoparasites to the host bird. Although, several endogenous and exogenous factors may have an accumulative influence on the parasitisation of both sexes of the village chickens by these parasites, such as host's hormones and humoral compounds, age and nutritional state, behaviour and habits, as well as the season of the year and ecological and physical features 
of the regions (Hasson, 2015). However, this present study was unable to detect or categorize the prevalence of avian haemoparasites in village chickens based on age of birds. This is because the study limited its scope to blood samples collection from adults village chickens presented for slaughter at the poultry markets/dressing slabs in the study area.

\section{CONCLUSION}

The study which is first of its kind in Maiduguri confirms the presence of avian haemoparasites genera of Haemoproteus species and Plasmodium species among adult Village chickens of both sexes presented for slaughter at poultry markets/dressing dressing slabs in Maiduguri, North-eastern Nigeria. As such, microscopic detection of avian haemoparasite gametocytes within Chicken RBC calls for attention in the study area. Despite carrying out the study during the dry season period which was considered a non-breeding season for most arthropod vectors, especially the mosquitoes, $17 \%$ prevalence rate was recorded. The infection is more among the male chickens and female chickens which revealed both sexes shared equally chances of getting infected with both detected blood parasites. The fact that this study limited its scope to investigation of parasites in adult chickens, occurrence of the parasites in young chickens should not be under estimated since both age groups mingle together at all times of the days and nights, therefore sharing equal chances of exposure to arthropod vectors that transmit the infection. Although, this call for further parasitological investigation by researchers in the study area.

\section{CONFLICT OF INTEREST}

The authors declare that they have no conflict of interest.

\section{REFERENCES}

Al-Barwari, S., \& Saeed, I. (2012). The parasitic communities of the rock pigeon Columba livia from Iraq: component and importance. Turkiye Parazitol Derg. 36(4), 232-239.

Archawaranon, M. (2005). First report of haemoproteus spp. in hill mynah blood in Thailand. Inter. J. Poul. Sci., 4(8), 523525.

Bebora, L. C., Mbuthia, P. G., Macharia, J. N., Mwaniki, G., Njagi, L. W., \& Nyaga, P. N. (2005). Appraisal of Indigenous chicken's potential in egg production. The Keny Veterinarian, 29, 10-13.

Bell, J. A., Weckstein, J. D., Fecchio, A., \& Tkach, V. V. (2015). A new real-time PCR protocol for detection of avian haemosporidians. Parasites and Vectors, 8, 383.

Benedikt, V., Barus, V., Caek, M., Havlicek, M., \& Literak, I. (2009). Blood parasites (Haemoproteus and microfilariae) in birds from the Caribbean slop of Costa Rica. J. Acta
Parasito., 54(3), 197- 204.

Braga, E. M., Silveira, P., Belo, N.O., \& Valkiūnas, G. (2011). Recent advances in the study of avian malaria: An overview with an emphasis on the distribution of Plasmodium spp. In Brazil. Memorias Instituto Oswaldo Cruz. 106, 3-11.

Cardona, C. J., Ihejirika, A. \& McClellan, L. (2002). Haemoproteus lophortyx infection in Bobwhite quail. Avian Diseases. 46(1), 249-255.

Cheesbrough, M. (2000). Protozoology. District laboratory practice in tropical countries. Low-price edition, UK. 1, 134140.

Dunn, J. C., Cole, E. F., \& Quinn, J. L. (2011). Personality and parasites: Sex-dependent associations between avian malaria infection and multiple behavioral traits. Behavioral Ecology and Sociobiology. 65, 1459-1471.

Gimba, F., Zakaria, A., Mugok, L. B., Siong, H. C., Jaafar, N., Moktar, Maizatul, A., Abdul Rashid, A. R., Amlizawaty, A., Abu, J., Sani, R. A., Amin-Babjee, S. M., \& Sharma, R. S. (2014). Haemoparasites of Domestic Poultry and Wild Birds in Selangor, Malaysia. Malaysian Journal of Veterinary Research, 5(1), 43-51.

Hasson, R. H. (2015). Haemosporidians parasites of Gallus domesticus, poultry in Iraq. International Journal of Advanced Research, 3(8), 1046-1054.

Karamba K. I., Kawo A. H., Dabo N. T., \& Mukhtar M. D (2012). A survey of avian malaria parasite in Kano State, Northern Nigeria. International Journal for Biotechnology and Molecular Biology Research. 3(1), 8-14,

Kiptarus, J. K. (2005). Focus on Livestock sector: Supply policy framework strategies, status and links with value addition. Workshop on value Assess food and export investment. Held at Grand Regency hotel, Nairobi, Kenya. $3^{\text {rd }}$ March 2005.

Knowles, S. C. L., Wood, M. J., Alves, R., Wilken, T. A., Bensch, S., \& Sheldon, B. C. (2011). Molecular epidemiology of malaria prevalence and parasitaemia in a wild bird population. Mol. Ecol.; 20, 1062-1076.

Mapiye, C., Mwale, M., Mupangwa, J. F., Chimonyo, M., Foti, R., \& Mutenje, M. J. (2008). A Research Review of Village Chicken Production Constraints and Opportunities in Zimbabwe. Asian-Aust. J. Anim. Sci. 21(11), 1680-1688

Marzal, A., De Lope, F., Navarro, C., \& Møller, A. P. (2005). Malarial parasites decrease reproductive success: An experimental study in a passerine bird. Oecologia, 142, 541545.

Merino, S., Moreno, J., Sanz, J. J., \& Arriero, E. (2000). Are avian blood parasites pathogenic in the wild? A medication experiment in blue tits (Parus caeruleus). Proceedings of the Royal Society of London B: Biological Sciences, 267, 25072510.

Møller, A. P., \& Nielsen, J. T. (2007). Malaria and risk of predation: a comparative study of birds. Ecology, 88, 871881.

Muchadeyi, F. C., Sibanda, S., Kusina, N. T., Kusina, J. F., \& Makuza. S. (2005). Village chicken flock dynamics and the contribution of chickens to household livelihoods in a smallholder farming are in Zimbabwe. Trop. Anim. Health Prod. 37(4), 333-334.

Njunga, G. R. (2003). Ecto- and haemoparasites of chicken in Malawi with emphasis on the effects of the chicken louse, Menacanthus cornutus. MSc thesis. The Royal Veterinary and Agriculture University, Denmark.

Opara, M. N., Ogbuewu, I. P., Iwuji, C. T., Njoku, L., Ihesie, E. K., \& Etuk, I. F. (2012). Blood characteristics, microbial and gastrointestinal parasites of street pigeons (Columba livia) in 
Owerri Imo State, Nigeria. Scientific Journal of Animal Science, 1(1), 14-21.

Page S., \& Daniel, C. (2000). The chicken book. University of Geogia press. Pp. 345-369

Permin, A., Esmann, J. B., Hoj, C. H., Hove, T., \& Mukatirwa, S. (2002). Ecto-, Endo- and Haemoparasites in free range chicken in the Gomoronzi District in Zimbabwe. Preventive Veterinary Medicine, 54, 213-224.

Poulsen, J., Permin, A. Hindsho, O. Yelifari, L. Nansen, P., \& Bloch, P. (2000). Prevalence and distribution of gastrointestinal helminths and haemoparasites in young scavenging chickens in upper eastern region of Ghana, West Africa. Preventive Veterinary Medicine, 45, 237-245.

Sabuni, Z. A., Mbuthia, P. G., Maingi, N, Nyaga, P. N., Njagi, L. W., Bebora, L. C., \& Michieka, J. N. (2011). Prevalence of haemoparasites infection in indigenous chicken in Eastern Province of Kenya. Livestock Research for Rural Development. Volume 23, Article \#238. (http://www.Irrd.org//rrd23/11/sabu23238.htm).

Sadiq, N. A., Adejinmi, J.O., Adedokun, O.A., Fashanu, S. O., Alimi, A. A., \& Sofunmade, Y. T. (2003). Ectoparasites and haemoparasites of indigenous chicken (Gallus domesticus) in Ibadan and environs. Tropical Vet., (21), 187-191.

Sanz, J. J., Arriero, E., Moreno, J., \& Merino, S. (2001). Female hematozoan infection reduces hatching success but not fledging success in Pied Flycatchers Ficedula hypoleuca. Auk., 118, 750-755.

Schultz, A., \& Whittington, P. (2005). High prevalence of avian malaria infection to avifauna at Cape Receife, Eastern Cape, South Africa. Ostrich, 76, 56-60.

Shadan, H. A. (2013). Prevalence of Blood Parasites in Local Chickens in Qaradagh District, Sulaimani - Iraq. The Iraqi Journal of Veterinary Medicine, 37(1), 17-21.
Siong, H. C. Sharma, R., \& Babjee, S. M. A. (2010). Assemblages of Ectoparasites and Haemoparasites in the Gallus gallus Complex in Selangor, Malaysia. 5th Proceedings of the Seminar in Veterinary Sciences, 5 - 8 January 2010.

Sol D, Jovani R, \& Torres J. (2003) Parasite mediated mortality and host immune response explain age-related differences in blood parasitism in birds. Oecologia, 135(4), 542-7.

Soulsby, E. J. L. (1982). Helminth, Arthropods and Protozoa of Domesticated Animals. 7th edition.Baillire, Tindall. Pp. 35740.

Usmana, M., Fabiyia, J. P., Mohammeda, A. A., Merab, U. M., Mahmudaa, A., Alayandea, M. O., Lawala, M. D., \& Danmaigoro, A. (2012). Ectoparasites and haemoparasites of chickens in Sokoto, northwestern Nigeria. Scientific Journal of Zoology, 1(3), 74-78.

Valkiunas G, Anwar, A. M., Atkinson, C. T., Greiner, E. C., Paperna, I., \& Peirce, M. A. (2005). What distinguishes malaria parasites from other pigmented haemosporidians? Trends Parasitol., 21(8), 357-358. 